\title{
Gonçalo Cadilhe nos trilhos de Santo António em Portugal: intimidades de um olhar em Por Este Reino Acima. No primeiro trekking da História de Portugal
}

Resumo:

Figura sobejamente conhecida no palco da literatura de viagens portuguesa contemporânea com já quinze obras publicadas, Gonçalo Cadilhe centra-se em questões de natureza identitária, imagológica, espacial, textual e ontológica, recorrendo quase sempre ao formato da crónica jornalística, entre outras formas breves. Trata-se, pois, de um autor cuja escrita decorre de um trabalho com uma referencialidade espacial estruturante no texto de viagem, resultante de um olhar que se pousa sobre uma geografia física e humana. Assim, partindo da obra Por este reino acima. No primeiro trekking da História de Portugal (2020), procuro problematizar o seu olhar sobre o interior do Portugal atual, ao longo da sua caminhada nos passos do jovem Santo António, visando recolher não apenas as imagens do país, bem como sublinhar a sua estreia pelas malhas da narrativa ficcional, já que o livro centra-se no primeiro trekking de um escritor português pelos territórios geográficos lusos e pela metaficção historiográfica, na recriação da biografia de Santo António num trajeto pelo espaço textual onde se ergue uma escrita porosa, apostando na convergência entre o real e a ficção ou tão só numa "frictional literature" (Ette 2003:31).

Palavras-chave:

Gonçalo Cadilhe, Santo António, ficção e referencialidade, literatura de viagens, metaficção historiográfica

Abstract:

A well-known figure on the stage of contemporary Portuguese travel literature with already fifteen published works, Gonçalo Cadilhe focuses on issues of identity, imagology, space, textual and ontological nature, almost always using the format of the journalistic chronicle, among other brief forms. In fact, this is an author whose writing emerges from a work with a structural spatial referentiality in the travelogue, as a look that comes to rest on a physical and human geography. Thus, starting from the work Por este reino acima. No primeiro trekking da História de Portugal (2020), I intend to problematize the author's gaze on the 
interior of Portugal today, along his walk in the footsteps of young Santo António, aiming to collect, not only the current images of the country, but also to underline his debut through the webs of fictional narrative. Above all, the book focuses on the first trekking of a Portuguese travel writer through national geographic territories and historiographic metafiction, on the recreation of the biography of Santo António on a journey through the textual space where a porous writing arises, betting on the convergence between the real and the fiction or just a "frictional literature" (Ette 2003:31).

Keywords:

Gonçalo Cadilhe, Santo António, fiction and referentiality, travel literature, Historiographic Metafiction

Que o português médio conhece mal a sua terra - inclusive aquela que habita
e tem por sua bem sentido próprio - é um facto que releva de um mais genérico
comportamento nacional, o de viver mais a sua existência do que compreendê-la.
Eduardo Lourenço

Santo António foi o primeiro grande viajante desta nação nascente, o primeiro português a afirmar-se como tal nas estradas do mundo, o primeiro que nos séculos seguintes alcançaria os lugares mais remotos do planeta, e curiosa ironia da História, levaria com ela o culto e a proteção do santo Português. Gonçalo Cadilhe

Encarado como uma das figuras mais emblemáticas no palco da Literatura de Viagens contemporânea portuguesa, marcado por um percurso de escrita e de viagem de mais de vinte anos a viajar pelo mundo, Gonçalo Cadilhe conta já com quinze de obras publicadas, recorrendo quase sempre ao formato da crónica jornalística, entre outras formas breves, como o diário, a carta, as notas reflexivas, as micronarrativas, só para citar algumas.

Construtor de cartografias afetivas em torno de um planisfério pessoal fruto de uma aturada organização prévia, viajando sempre em trânsito fronteiriço, o autor consolida a sua imagem de escritor-viajante nessa forma de escrita polimórfica, característica de uma literatura híbrida, rente às circunstâncias do quotidiano e dos percalços do ato viático, entendido como um espelho de figuração da alteridade. Ademais, tratando-se de um escritor de ofício múltiplo, Cadilhe dá voz e visibilidade a uma produção, por vezes, multimodal e/ou intermedial a que já nos habituou: cronista das revistas Única do semanário Expresso e Fugas do jornal Público, entre outras publicações no âmbito dos periódicos (onde deu os primeiros passos) e no espaço editorial, ocasionalmente, assumindo as funções de biógrafo itinerante, outras de investigador historiográfico, ${ }^{1}$ algumas de realizador televisivo e/ou documentarista, ${ }^{2}$ outras ainda de fotógrafo de viagens ${ }^{3}$ 
e até de viagem de autor viajante temático, contratado por algumas empresas ou agências de viagem. ${ }^{4}$

Tratando-se de um autor que faz das viagens o seu iter e, portanto, o seu modus vivendi com intensa experiência de deslocação no espaço físico, nos seus livros a viagem emerge como o tópico axial, privilegiando questões como a identidade, a representação do Outro, as paisagens geográficas e humanas, numa incessante demanda ontológica, textual e/ou intermedial, decorrentes de um trabalho com uma referencialidade espacial estruturante no texto viagístico, resultante de um olhar que se pousa sobre uma geografia física e humana.

Considerando quer as indagações genológicas em torno da literatura viática, da relação entre a viagem e a literatura, da História e da biografia ou tão-só da metaficção historiográfi$c a,{ }^{5}$ quer a problematização de questões identitárias, imagológicas, interculturais e textuais, analisadas num contexto de fronteira e de interstício, ${ }^{6}$ a verdade é que Cadilhe granjeou um significativo reconhecimento da crítica e do público em geral, ${ }^{7}$ contribuindo para a captação de um leitorado fiel, seduzido pela especificidade do seu olhar instigante e pluriperspetívico do homo viator, ressumbrado em obras urdidas numa estratégia fragmentária, corporizada numa escrita dúctil, vigorosa e proteiforme.

Face a toda uma produção que assenta na experiência viática pessoal, impõe-se procurar entender as motivações - ainda que sucintamente -, que levaram um escritor-viajante português do século XXI a interessar-se por narrativas que não apenas incluem o tópico da viagem acontecida com maior ou menor tendência efabulatória, mas que, particularmente, visam reabilitar o nosso património histórico cultural coletivo através das biografias e das memórias de figuras incontornáveis que promoveram uma nova imagem de Portugal no mundo. Como sublinha Eduardo Lourenço:

Se a História, no sentido restrito de «conhecimento do historiável», é o horizonte próprio onde melhor se apercebe o que é ou não a realidade nacional, a mais sumária autópsia da nossa historiografia revela o irrealismo prodigioso da imagem que os Portugueses fazem de si mesmos. (Lourenço 2020: 23)

Não por acaso, quando em 2008, Gonçalo Cadilhe publica o seu primeiro livro em torno da figura de Fernão de Magalhães, já nessa altura se tornava claro o seu desejo de redescobrir um país que nos séculos XV e XVI celebrou a aventura mais exaltante dos Descobrimentos, ${ }^{8}$ a qual viria a ser a génese de um mundo novo para os europeus, rasgando o mar inexorável em busca do desconhecido, do exótico e da outra face do mundo. ${ }^{9}$ Tome-se esta breve referência geral à História na obra cadilhiana, como um ponto de partida para a compreensão do interesse na nação mais velha da Europa desde a sua fundação no século XII, fazendo dele um escritor-viajante empenhado em revisitar também o Portugal medieval na sua geografia física muito reduzida, propensa a deslocações num universo religioso e político que propiciava perseguições e fugas. Por isso mesmo, o autor decide revisitar a figura de Santo António, quando em 2016, publica Nos Passos de Santo António. Uma viagem Medieval, onde, em etapa introdutória, avisa: "Este olhar 
sobre Santo António não é o de um devoto, nem o de um historiador, nem o de um antropólogo. Este é o olhar de um viajante" (Cadilhe 2016: 13). Nada afinal, de completamente extraordinário, se considerarmos que o santo nascido em Lisboa foi também um viajante que levou o nome de Portugal ao mundo.

Se, na sobredita obra, firmada numa cartografia prévia minuciosamente preparada, com início em Coimbra e termo em Pádua, fruto de uma aturada pesquisa bibliográfica (idem: 187188) e também do recurso aos testemunhos fornecidos por personalidades da igreja, académicos, entre outras, (idem: 13-15), o autor parte de Portugal para o exterior no rasto do santo português, a verdade é que nesta sua última publicação - Por Este Reino Acima. No primeiro trekking da História de Portugal (2020) -, Cadilhe retoma a viagem de Santo António, mas agora num roteiro nacional e, no sentido inverso do primeiro, privilegiando uma poética dos lugares e dos "não-lugares"10 (Augé 2005: 67) de Portugal, observando as terras e as gentes, as cidades e os campos, redescobrindo um mosaico variegado do país através da lente de viajante e escritor, a partir de um livro que se revela um corpus de investigação estimulante na literatura viática portuguesa contemporânea.

Dado à estampa em 2020, Por Este Reino Acima. No primeiro trekking da História de Portugal ergue-se novamente em torno da biografia de Santo António, ${ }^{11}$ tendo então Portugal como destino de eleição, num contexto geográfico doméstico, percorrendo um trajeto de Lisboa até Coimbra, em que o autor envereda mais uma vez pelos trilhos da metaficção historiográfica (Hutcheon 1988), de índole hagiográfica, numa viagem à nação medieval, numa peculiar revivescência do tempo e do espaço. Como escreve o narrador, "[...] caminho por esta artéria milenária como se também eu tivesse apenas quinze anos, me preparasse para enfrentar uma viagem perigosa, longa e cansativa até Coimbra, e me despedisse de Lisboa sem saber se a voltaria a rever alguma vez" (Cadilhe 2020: 28).

Resultado de uma sustentada e reforçada pesquisa histórica sobre a biografia de Santo António, neste livro, Cadilhe segue o modelo estruturante dos anteriores, lançando mão de um jogo de fragmentos incorporados num diário, mesclando-os com traços de outras formas breves, recorrendo ao tradicional espaço liminar com a presença dos elementos paratextuais: "Nota Introdutória" (idem: 13-16), um mapa com desenhos ilustrando lugares, figuras e momentos-chave do relato e/ou do trekking (idem: 2-3) e a "Biografia Breve" de Santo António (idem: 17).

De facto, tais elementos, para além de emergirem como um leitmotiv à leitura do texto principal, fornecendo um conjunto de informações a um leitorado formatado por interesses comuns, assumem também função de reforçar, não apenas uma ancoragem histórica da caminhada, mas, sobretudo, a de autentificação do relato, contribuindo assim para a legitimação da obra, ao nível do seu acolhimento pela crítica literária.

É ainda de sobrelevar a inclusão de vinte e três fotografias da viagem, ${ }^{12}$ claramente reveladoras da captura dos locais e de figuras marcantes do seu itinerário, nas quais a lente de Cadilhe regista as suas observações numa sintaxe fotográfica da caminhada num interessante cruzamento com a viagem do Santo, confirmando-se assim o significativo recurso ao dispositivo 
fototextual, pois como sublinha Susan Sontag, "As imagens fotográficas são peças testemunhais de uma biografia ou de uma história em devir. E, ao contrário da pintura, uma fotografia implica fotografias futuras." (Sontag: 2012: 162)

Tais elementos comprovam assim a sua inscrição na Literatura de Viagens, ${ }^{13}$ numa obra que espelha a especificidade do próprio olhar do escritor-viajante sobre a condição do Portugal do século XXI, com base na memória do património cultural histórico coletivo e pessoal, bem como construindo a personagem do santo viajante português com lídima tendência para a efabulação e, portanto, num impulso estimulante de narrativa ficcional. De resto, tal estratégia não é nova e vai ao encontro da obra matricial de Almeida Garrett Viagens na Minha Terra (1846), ${ }^{14}$ em particular, ao processo de interligação das sequências narrativas por encaixe, corporizado na novela da "menina dos rouxinóis", entre outros aspetos, o que em muito denota a influência garrettiana na obra, pois a narrativa ficcional cadilhiana vai sendo fragmentariamente encaixada na narrativa viática, abrangendo o período dos oito dias de duração da mesma. Ou seja, Cadilhe opta por uma organização narratológica por encaixe ainda que sempre em alternância com os pontos cardeais da sua deslocação, em convergência com a retoma da viagem de Santo António, sempre num paralelismo situacional até ao seu desfecho e/ou conclusão com a chegada a Coimbra (idem: 191-192).

Na verdade, partindo do relato da viagem realmente acontecida Tejo arriba, na subtil evocação garrettiana, Cadilhe toca com hábil mestria o território da narrativa ficcional ao incluir a biografia do pequeno António (idem: 15) através da viagem medieval - grafada em itálico - , num processo de metaficção, refletindo a sua visão da História e da realidade portuguesas, ressuscitando-as e recriando-as a partir da sua própria viagem retranscrita, pelo espaço físico, textual e imaginário, em torno da biografia do santo português:

Sorrio com as tentativas de paralelismos que tenho vindo a construir nestes dias entre as minhas experiências de vida e as que ando a ficcionar para Santo António, baseando-me naturalmente em tudo que me parece plausível ou que está historicamente provado, tal como fui expondo no meu livro Nos Passos de Santo António. (idem: 123-124)

Se bem que esse movimento de escrita do sujeito viático ao assumir também a função de ficcionista acabe por manter uma continuidade fragmentária descontínua ao longo dos oito dias de caminhada inscritos no diário, é no seu próprio hibridismo que a permanente relação entre ambas as viagens mais se atualiza através de notas e/ou impressões, resultantes da cartografia visitada, como esclarece: "Através dos nomes dos lugares que atravessei, a minha caminhada conecta-se a um passado mítico de construção e consolidação de uma pátria" (idem: 179) ou ainda na reflexão: "Subo pela esquerda da Sé, em direção a São Vicente de Fora. Estou extremamente alerta e, paradoxalmente, tenho a atenção dispersa por várias linhas de pensamento" (idem: 23).

Com efeito, o que torna este livro caso singular na produção viagística do experiente globetrotter, é o facto de eleger o trekking em Portugal seguindo os passos do jovem Fernando 
Martins,${ }^{16}$ por um lado, apostando em conselhos e técnicas sobre a arte de caminhar e, por outro, aventurando-se pelas malhas da metaficção historiográfica, autorizando equacionar questões genológicas numa obra que per se dá visibilidade a uma "escritura fronteriza" (Zavala 2006: 35), dada a sua forte porosidade e fluidez, numa clara inscrição no hibridismo da Literatura de Viagens ou na conhecida expressão de Otmar Ette, numa "frictional literature" (2003: 31).

Regressando à arquitetura diarística do livro, impõe-se notar que a narrativa obedece a uma sintaxe cronológica de oito dias de caminhada, centrando-se ora nos acontecimentos ocorridos durante o itinerário, reflexões, excursos históricos e impressões do eu-textual ora na estória e/ou biografia ficcionada do santo em absoluta autogestão, originando assim um relato intimista assente na linearidade temporal dos factos, produzindo, deste modo, um efeito de espelhamento instituído na dialética autor-empírico-autor-textual, implicando implícita ou expressamente o leitor num "pacto autobiográfico" (Lejeune 2005: 27). Com efeito, sublinha Fernanda Irene Fonseca:

[...] o tema do diário é sempre, antes de tudo mais, o seu autor, ou melhor a criação de uma imagem que o eu enunciador quer deixar de si próprio num género de escrita em que o leitor é envolvido pelo autor num pacto - «o pacto autobiográfico» - que estabelece uma identidade entre o autor, o narrador e a personagem que a própria escrita cria. (Fonseca 2008: 11)

O autor lança as linhas mestras de Por Este Reino Acima com várias sobreposições narratológicas do tópico da viagem: a caminhada do sujeito textual per se, imbuída de uma forte referencialidade fruto da deslocação acontecida, tendo por base a experiência das paisagens geográficas e humanas; as abundantes divagações e digressões do narrador (idem: 21, 22,...); os excursos históricos (idem: 27,29...) e biográficos (idem: 30...); a livre criação de um curto enredo ficcional em torno da figura do pequeno António, ${ }^{17}$ correspondente apenas a trinta e quatro páginas do tempo do discurso, que se vão espraiando ao longo dos oito dias da caminhada numa escrita "intencionalmente fragmentária" e descontínua (Fonseca 2004: 345), da qual resulta uma trama ficcional, corporizada numa tessitura de fragmentos integradores do texto-fonte, ${ }^{18}$ assentes numa linearidade de sentido, garantindo uma estrutura interna, firmada na totalidade formal e semântica, temporal e espacial.

Não por acaso, a obra cumpre o ciclo viático do itinerário - partida - viagem - chegada - , permitindo um interessante entrelaçamento com a narrativa ficcional, acionando assim uma dinâmica intratextual, assente na alternância de ritmos narratológicos, como estratégia de captação do leitor, impelido a seguir a proposta de incipit (idem: 31-33), numa clara imiscuição no universo ficcional da viagem e na biografia do santo, ${ }^{19}$ como lembra o narrador:

Como terá sido a viagem de Santo António? Posso ficcionar um possível quadro de marcha a partir do pouco que sei do terreno e do pouco que li sobre a época. Suponhamos que esperou companhia, organizada pelos seus superiores do convento de São Vicente de Fora. Que tipo de viajantes estaria na estrada com o monge noviço que mudava de morada? [...] 
Gosto de pensar que, pelo contrário, dada a figura humilde do pequeno cónego de Santo Agostinho, não tenha havido uma preocupação muito grande com a sua segurança. No entanto, talvez tenha tido pelo menos um companheiro de viagem. Um homem que conhecesse a estrada, que já outras vezes teria palmilhado a distância entre as duas cidades. [....]

O comerciante, Sisnando Meireles, soubera através do seu confessor agostiniano que um extraordinário aluno de São Vicente de Fora, um certo Fernando Martins, pedira para ser transferido para Santa Cruz de Coimbra, onde poderia prosseguir os seus estudos na célebre biblioteca do mosteiro. (idem: 31-32)

Introduzida a estória do pequeno António no Dia 1 da viagem, é de notar que a divisão da obra em oito dias de percurso, remete-nos ainda para uma fusão temporal: o presente do narrador e o passado do santo, que, ao "reencontrarem-se" nos mesmos espaços, dão origem ao cenário simbólico da ficção, representado pelo lugar da escrita ou tão-só da biografia ficcionada do jovem Fernando Martins. Neste sentido, a perícia do autor reside na articulação hábil entre o seu discurso em etapa introdutória e essa narrativa biográfica apresentada, estabelecendo inequivocamente o seu pacto com o leitor:

Assim, espero que esta proposta de seguir o Caminho do pequeno Santo António, desde a Sé de Lisboa até ao Mosteiro de Santa Cruz de Coimbra, venha a ser adoptada por amantes do trekking espiritual, caminhantes peregrinos, membros da tribo global do turismo de trekking. Mas, acima de tudo, espero que seja adoptada por ti. Foi para isso que escrevi este livro! (idem: 16)

Estamos, pois, perante um livro que promete ao leitor mais do que uma viagem partilhada por terras lusas da atualidade, o "primeiro trekking da História de Portugal", instigando-o a um "[...] reencontro com as paisagens, a História e os ambientes culturais da [sua] pátria" (idem: 15), incidindo no "[...] itinerário que decalca três vias institucionais bem celebrizadas de matriz religiosa: O Caminho Central Português de Santiago; Os Caminhos de Fátima; e a Rota das Carmelitas." (ibidem). Na verdade, é também propósito do autor apresentar a sua faceta de ficcionista através da biografia efabulada do pequeno António "[...] fio condutor à obra." (ibidem).

Construído em torno do binómio viagem real e viagem ficcional, neste livro, Gonçalo Cadilhe encarna um percurso ontológico, espiritual enveredando agora pela escrita ficcional, ${ }^{20} \mathrm{bem}$ como espelha a especificidade do seu olhar na (re)construção das imagens e da identidade do país atual, na sua diversidade, numa trajetória também de (auto)-redescoberta:

A minha caminhada demorou oito dias e foi uma peregrinação no sentido mais lato do termo: não religiosa, mas certamente espiritual. Foi também um reencontro com as paisagens, a História e os ambientes culturais da minha pátria. E foi um longo, preguiçoso devaneio por memórias e momentos formativos da minha vida. Foi portanto uma experiência pessoal e bastante introspetiva, mas tão luminosa e inspiradora que quis que fosse partilhada contigo. (idem: 15) 
Paralelamente, o escritor-viajante traça o retrato do país contemporâneo através das imagens produzidas ao longo da sua deambulação pelas paisagens humanas e geográficas, privilegiando um registo divagacional, no qual, reflete sobre a condição sociocultural, económica e política de Portugal no século XXI. Estas imagens resultam também da convocação de uma biblioteca mental de que ressalta uma inspirada(ora) intertextualidade, ${ }^{21}$ transportando o leitor a uma nação olhada de fora para dentro, mas também de modo inverso. Senão vejamos.

Se tivermos em conta o primeiro caso, impõe-se destacar a referência ao escritor britânico Paul Hyland (1997), a propósito do papel axial do rio Tejo (idem: 75) na formação da identidade nacional, induzindo o narrador a concluir que "Afinal, este rio foi sempre artéria vital da nacionalidade, não apenas em sentido estratégico, mas na essência da ideia que criámos de nós próprios e da pátria à qual pertencemos" (ibidem). Por seu lado, apostando num olhar interno do país que supera a sua condição territorial e temporal, Cadilhe ora reescreve e atualiza a visão do Portugal do Estado Novo assumindo a lente do neorrealista Alves Redol, "Cruzo-me com duas velhotas viúvas vestidas como num romance de Alves Redol. Neo-Realismo em estado bruto" (idem: 94), ora numa singela homenagem evoca José Saramago (idem: 94-96), aquando da sua passagem pela sua casa natal, entre outras referências pontuais a acontecimentos históricos e a figuras da nossa cultura (idem: 27, 123), sempre recorrendo à validação pela confirmação das fontes de historiadores como José Mattoso et al., na obra Portugal - o Sabor da Terra (2011) (idem: 39-40), entre outros exemplos. Trata-se, pois, de um livro constituído por uma profusão de narrativas de viagem fragmentárias gerenciadas por um roteiro previamente elaborado, pensado em revisitar o espaço da memória e, em simultâneo, focado em urdir a trama ficcional da deslocação do pequeno António, num jogo de espelhos em que narrador autodiegético e personagem se entreolham de muito perto à distância de nove séculos.

Partindo então de uma cartografia previamente organizada, o sujeito viático assinala o Dia 1 como a partida (idem: 19-46) para a caminhada, começando por Lisboa com destino a Coimbra orientada pelas "velhinhas cartas do exército" (idem: 36), tecendo considerações de ordem ontológica, espiritual, histórica, social e geográfica e até imagológica (se tivermos em conta a auto-representação do viajante-textual assumindo o papel do português, turista acidental no seu país) para cumprir o percurso, elegendo a Estrada Nacional 1 (idem: 19). Note-se a seguinte reflexão do sujeito viático sobre a cidade de Lisboa:

[....] caminho entre turistas com a mesma sensação de descoberta de uma cidade estrangeira. Também não me sinto português, talvez por - apesar de me manter dentro do meu país - estar efectivamente em viagem. Muito menos sinto que este seja um dia de trabalho, embora o meu trabalho seja viajar e escrever sobre isso. Sinto que me foi dada a possibilidade de, durante uma manhã, usufruir de uma perspetiva sobre Lisboa que não tem pontos de referência nem categorias. Sou alguém ao lado de tudo o resto. Nem visitante, nem autóctone; nem de férias, nem em trabalho; nem peregrino disposto a sofrer. (idem: 24) 
Com efeito, O Dia 1 é constituído por um conjunto de vinte e um fragmentos de viagem, reservando dois à ficção sobre o Santo. Logo, nos primeiros dezassete, o narrador situa a partida de Lisboa, traçando uma imagem atualíssima da cidade natal de Fernando Martins, marcada pela gentrificação, entre críticas sociais outras ao poder socioeconómico e político (idem: 34-35), a par de excursos históricos, até chegar à Lezíria, incluindo o encaixe da narrativa ficcional (idem: 30-31), retomando-a mais tarde (idem: 40-41), na qual introduz as duas personagens: o pequeno António e D. Sisnando, seu companheiro de viagem.

De notar que Gonçalo Cadilhe enfatiza os excursos históricos sobre a cidade de Lisboa (idem: 19-31; 33-40; 41-46), numa contextualização in loco e através da bibliografia consultada (idem: 39-40), construindo um itinerário completo percorrido como um flâneur, como escreve o narrador: "Observo, curioso e ingénuo, o charme da cidade de Lisboa medieval, deixo-me encantar como qualquer outro turista de passagem; mas mantenho elevada a exigência, e implacável o cepticismo sobre a veracidade desse charme [...]" (idem: 24). Apresentadas as coordenadas de partida e o plano de atravessar o rio Trancão, a decisão é apanhar o comboio e descer em Alhandra (idem: 42-43). Seguem-se, reflexões sobre a distinção entre turista e viajante (idem: 44-45) e, finalmente, o último excerto dá conta da chegada do caminhante a Vila Franca de Xira e à pernoita no hotel (idem: 45-46).

O Dia 2 (idem: 47-60) é constituído por nove fragmentos de viagem (idem: 47-54 e 5560) e pela retoma da narrativa ficcional (idem: 54-55), relatando a progressão da viagem e o contacto com a população com trajetos feitos pelo rio Tejo rumo ao norte, como observa o narrador:

Ao evocar uma viagem medieval, reparo que a minha imaginação se debruça concretamente sobre uma viagem medieval portuguesa - desse Portugal que começa no Tejo e continua até tocar no Mediterrâneo. Com esta luz, com este vento, com esta paisagem e vegetação, nunca poderia pretender estar a viajar, fosse no tempo ou no espaço, em qualquer outro lugar que não o pedaço meridional do meu país. Por vezes as viagens mais gratificantes acontecem à porta de casa. (idem: 53-54)

O Dia 3 (idem: 61-76) é, por sua vez, constituído por sete fragmentos de viagem (idem: 6171), marcando o avanço em direção a Porto de Muge, onde o sujeito textual se cruza com os habitantes num bar, "Rudes, desdentados, obesos na pança, escanzelados no rosto, anacrónicos" (idem: 67), a maculada imagem do seu Portugal contemporâneo, dando a ver a sua reprovação, espelhando a ironia e a paródia ou simplesmente a crónica de um país real, incompatível com a cultura, como escreve o narrador cadilhiano: "De um lado temos um escritor que depende do mercado livreiro português para sobreviver; do outro, um bebedor matinal de bagaço. Qual deles irá extinguir-se primeiro?" (idem: 68). Assim, no contexto presente, confirma-se a crítica corrosiva de Cadilhe ao estado de atual do Portugal profundo, marcado por uma espécie de imobilismo subcutâneo, inconciliável com uma atitude cosmopolita. 
Outras notas de natureza histórica e toponímica seguem também a sua rota, até nova retoma do fio diegético da narrativa ficcional (idem: 71-72), na qual as duas personagens abordam questões religiosas sobre os mistérios da vida e da morte de acordo com as crenças teocêntricas medievais num Deus punitivo, assegurando somente uma viagem com ausência de coordenadas geográficas e permitindo tão-só a tríade céu, purgatório e inferno, tal como esclarece o pequeno Fernando: "- Purgatório, senhor. É uma espécie de antecâmara do Céu, um lugar onde as almas dos justos podem ficar vários anos ou séculos a expiar as suas penas menores para então ganharem a pureza necessária dos santos e de Deus Nosso Senhor." (idem: 72) Após este momento de diálogo entre as personagens da viagem ficcional, o sujeito textual regressa ao relato alusivo à caminhada com destino a Santarém, onde medita sobre a sua condição de viajante e escritor: "Defini-me como escritor que caminha." (idem: 73-76) Este termina com as considerações do viajante-textual que se entrega aos queixumes dos árduos efeitos do trekking no corpo, ao mesmo tempo que tece umas curtas digressões sobre a condição humana e a consciência da sua finitude, e a vida como metáfora da viagem, entre reflexões outras sobre a caminhada e a peregrinação numa assunção ontológica em que se destaca a descoberta do peregrino que brotou de dentro de si (idem: 76).

O Dia 4 (idem: 77-102) integra dezanove fragmentos da deslocação geográfica subdivididos da seguinte forma: dois abrangem a saída de Santarém pela estação ferroviária, notas soltas sobre a ponte medieval de Alcôrce (idem: 78), seguindo-se a narrativa do jovem santo (idem: 79-80) num paralelismo perfeito: "- Dom Sisnando, Coimbra tem ponte? - Claro que sim, rapaz. A melhor ponte do nosso reino!" (idem: 80); três fragmentos relatam a travessia da ponte e a caminhada à noite em que o sujeito viático alcança uma experiência transcendental: "A síntese do que me tornei salta-me com naturalidade da mente. Eis o seu resumo: caminha até te sentires parte do próprio caminho!" (idem: 81); sucede-se um episódio de um dia de caça e de perigosidade para o trekker incauto que se desloca naquele espaço, o que o leva a interrogar-se: "Como é possível em pleno terceiro milénio ainda persistir na mentalidade portuguesa o prazer da morte do animal?" (idem: 83)

Questões como esta e outras, captadas do quotidiano, perpassam ao longo deste fragmento, denotando as inquietações de um autor desassossegado com uma identidade marcada por um certo mofo do atraso provinciano, maculada pela incivilidade e pela incultura dos portugueses, quase que numa leve evocação camoniana nas reflexões do poeta. ${ }^{22}$ Nesta altura, retorna à estória do pequeno António, que instigará reflexões de índole teológica sobre os animais, defendidas por São Francisco de Assis, em contraste com a violência perpetrada contra eles no presente. Se António corporiza os preceitos da doutrina franciscana em profunda comunhão com a natureza ${ }^{23}$ (idem: 84-85), aqui, o narrador, numa engenhosa reviravolta, centra-se no tópico da barbárie que a caça e as touradas representam na sociedade portuguesa contemporânea, criticando corrosivamente as imagens que de Portugal resultam para uma grande faixa da população que rejeita tais práticas, decorrentes de um certo obscurantismo, herdado do regime salazarista, de políticas populistas e de algumas fações totalitárias, ainda muito presentes e até ressurgidas em certos setores da população. 
Regressando à viagem real e à sua incursão pelo território geográfico "por uma típica aldeia portuguesa" (idem: 85), Vale da Figueira, o sujeito viático vai consolidando o seu olhar de um Portugal campestre, pobre, despovoado, contudo, proporcionando paisagens de magnífica beleza no quadro pastoril da lezíria onde se depara com outros caminhantes, alguns estrangeiros, estimulados pela peregrinação a Fátima (idem: 86, 91), entre outros Caminhos religiosos. Seguidamente, surge a alusão aos habituais percalços do viajante com uma rota bem definida: Santarém, Azinhaga, Golegã (idem: 86-89).

Em relação a estas deslocações, importa salientar que elas representam um país narrado por dentro, através da lente de um autor português que observa bem de perto a realidade, recriando a narrativa do seu país e a viagem do pequeno António através da escrita.

O Dia 5 (idem: 103-127) é composto por treze fragmentos de viagem, dois momentos intercalares para a narrativa ficcional do santo (idem: 105-106 e 122-123) e é neste momento que o viajante assume a rota de outra metade do país a partir de Montejunto-Estrela, como indica: "Começo hoje, portanto, a caminhada pela folha amarrotada, embrulhada e comprimida que, ao tentar voltar à posição inicial, melhor ilustra a parte norte do meu país. Esta metáfora não é minha. É de Hernán Cortéz." (idem: 103). A propósito desta referência ao conquistador espanhol, Cadilhe continua a revelar um sabor épico da escrita da sua caminhada em deslocação dentro da sua pátria, agora numa paisagem geográfica transfigurada, "essa folha retorcida que é o Portugal Alto", bem como lembrar os heróis históricos, no quadro das suas leituras e pesquisas evocadas.

Ao continuar a sua caminhada, o sujeito viático dará início a uma travessia épica que envolve a serra de Aires e a serra da Melriça (idem: 104), tratando-se do momento em que anuncia o regresso a casa (ibidem). Neste caso, opta por um conjunto de fragmentos de viagem que irão centrar-se na descrição da paisagem de um país belo e onde o viajante-textual encontra as suas raízes. De notar que já em Atalaia, o narrador caminha junto à A23, esse "não lugar" (Augé 2005: 67) que contrasta com o ritmo do flâneur²4 que desenhou a marca do tempo em ampulheta própria (Cadilhe 2020: 126), escolhendo antes, a sua forma de viajar ao lado da autoestrada, como de resto, sublinha:

Paradoxalmente, a velocidade que desde sempre marcou o tempo de viagem, ou seja, o ritmo da caminhada, aparece-me agora como uma revelação, uma epifania e um segredo que não partilho com os condutores que desaparecem do meu campo de visão como relâmpagos, engolidos sob a ponte pedonal da auto-estrada. (idem: 107)

Já o Dia 6 (idem: 129-149) integra quinze fragmentos da caminhada do sujeito viático em direção a Tomar onde aproveita para exultar o património histórico e a inclusão nos roteiros do turismo, nos quais "[...] não há uma construção ardilosa da imagem medieval da cidade, nem um investimento forçado no apelo místico do seu passado, nem um exagero chauvinista quando nos referimos ao Convento de Cristo como um dos monumentos mais extraordinários da Europa." (idem: 129) 
À medida que caminha pelas ruas da cidade, o viajante tece considerações de ordem socio-histórica e urbanística, não deixando de estabelecer comparações com outras cidades europeias, como Nápoles, contribuindo assim para legitimar a sua viagem iniciática a Portugal na representação da unicidade da identidade portuguesa, pois o café pendente ${ }^{25}$ (idem: 130-131) napolitano não figura no imaginário luso da nossa cultura, entre outros exemplos. 0 momento seguinte do percurso que envolve o trilho do rio Nabão emerge como leitmotiv para a uma nota reflexiva sobre Santo António e para a apresentação da justificação da sua afeição: "Quem é para mim Santo António? [...] Para muitos é o santo dos milagres. Para mim, é o santo do caminho." (idem: 132) Eis aqui o surgimento da passagem à narrativa ficcional (idem: 132-133), na qual Cadilhe expõe a relação cordial entre as personagens e até paternalista por parte de Sisnando, ao mesmo tempo que propõe uma figuração física do jovem santo bastante humanizada, expondo o seu corpo nu no banho, incidindo na descrição de uma fisiologia anafada de acordo com os modelos estéticos do corpo da época e que indiciava alguém "[...] dispensado de se cansar de trabalhos físicos e tarefas manuais" (idem: 133), portanto, destinado ao conforto da vida monástica e erudita do mosteiro de Santa Cruz.

Seguem-se treze fragmentos do itinerário desenhado pelo autor, alguns dedicados à prática do trekking, sobretudo ao referir a excelente organização dos percursos no estrangeiro (idem: 135), deixando reparos à falta de estratégia dos portugueses em criar condições de segurança e conforto para os caminhantes, principalmente, em percursos como a Grande Rota da Serra do Caldeirão, a Travessia do Alvão ou ainda aos Caminhos de Fátima (ibidem). Visto pela lente do narrador, o turismo do trekking em Portugal revela muitas falhas, pelo que defende um estatuto dignificante, no qual os turistas ou caminhantes se sintam seguros e confortáveis na sua incursão no território geográfico natural e belo, bem como cultural e religioso, que reflita o imaginário lusitano.

Outros fragmentos deste dia seis sinalizam ao leitor os lugares de passagem, delineando o avanço da caminhada para o seu termo, não se coibindo de abordar os mais variados assuntos a partir da sua experiência de globettroter nas suas inumeráveis passagens e permanências no estrangeiro (idem: 136-141). De resto, enquanto escritor-viajante, Cadilhe tem agora Portugal no centro da sua deslocação e imaginário, olhando para si mesmo e para santo António do mesmo lado do espelho, em que realidade e ficção se dissolvem, num livro que reinventa a cartografia de um país que se vai revelando a cada passo. Entre paisagens bucólicas a evocar o locus amoenus do Classicismo (idem: 145), são também encontradas ténues referências ao Portugal romântico das Viagens garrettianas como no exemplo da velha que se cruza com o sujeito viático numa encruzilhada, fazendo-o parar pela superstição, envolvendo-o num halo sobrenatural: "Diz «que Deus abençoe o seu caminho». Depois, sorri, afasta-se e deixa-me passar. //Fico perturbado." (idem: 146)

O dia 6 encerra com a narração da viagem do pequeno António e Sisnando com a paragem em Alvaiázere, centrando-se agora o narrador na caracterização do protagonista, destacando as práticas e rituais religiosos da época como a autoflagelação e a tendência para a vida de eremita em comunhão absoluta com a natureza, contribuindo assim para a fabricação de um 
retrato epocal e que fazia do jovem Fernando Martins o santo viajante mais famoso (idem: 147-149).

Chegado, entretanto, ao Dia 7 (idem: 151-174), período que integra doze fragmentos relativos aos percalços da caminhada e um par de narrativas relativas à viagem ficcional, Cadilhe dedica algumas notas reflexivas ao trekking, aqui agora entendido na sua dimensão mística e de despojamento, no sentido que lhe é atribuído por São Francisco de Assis na sua pregação itinerante, afastada do conforto dos conventos e dos mosteiros, resgatando assim o retorno à pureza da primordialidade do homo viator na renúncia ao conforto e ao materialismo, como escreve o narrador:

O trekking tem esta vertente que é muito semelhante à pureza e ao despojamento dos primeiros tempos do franciscanismo. A opção de fundo do caminhante é sempre a de se espoliar da comodidade do meio de transporte e manter-se fiel às possibilidades das suas pernas. (idem: 151)

Seguem-se traços bem peculiares da narrativa viática com a alusão às experiências vividas durante a sua deslocação com mais ou menos tendência para a efabulação, neste caso, notas sobre o recurso aos transportes mais arcaicos: o barco e o cavalo ou o burro (idem: 154). Deparamo-nos assim com um episódio cómico e fortuito que Cadilhe introduz neste momento da viagem, apelando à comicidade provocada pela sua desastrosa estreia a montar a cavalo na sua passagem pela Quinta da Cortiça quando cruza com Zé Maria, o dono da respetiva quinta (idem: 152-157). Neste seu testemunho sobre a arte de não saber cavalgar toda a sela, o autor dá relevância ao acaso, visando obter efeitos de veridicção no relato retranscrito, criando assim um jogo ficcional ou frictional entre o narrador-viajante e o leitor, legitimado pela escrita.

Assim sendo, a introdução de acontecimentos inesperados permite ativar mecanismos de impressionabilidade, surpresa ou mesmo a criação de um efeito de sedução e cumplicidade latentes entre narrador e leitor, que podem envolver a natureza, figuras ou até mesmo o sobrenatural, aqui pensado num sentido místico e de crendice popular, como no já aludido exemplo do encontro inquietante do caminhante na encruzilhada com a velhota, ou ainda na descrição de ambientes de terror como o troço entre Alvaiázere e Ansião (idem: 159).

Por isso mesmo, o conjunto de fragmentos diversificados alusivos às experiências do narrador que se desloca no espaço e no tempo surgem intercalados e/ou interrompidos por notas de pendor reflexivo, excursos históricos, episódios relatando contactos efémeros e fugidios ou até mesmo pela descrição das paisagens rurais afetadas pela desertificação e consequente mudança de significante cultural do país, como observa o narrador: "Estas terras estão tetricamente desertificadas, mas em tempos históricos, e mesmo até há décadas recentes, eram habitadas [...]. Hoje, as aldeias estão vazias, os campos abandonados, os bosques deixados ao mato selvagem, as pessoas emigradas para grandes cidades, países distantes" (idem:159-160).

Com efeito, Cadilhe relembra e toca na questão da emigração ou da diáspora portuguesas, um dos pontos mais nevrálgicos da realidade histórica do século XX, e comenta as consequências nefastas ao nível demográfico e social, acrescidas de repercussões negativas traduzidas 
no trauma do abandono da terra natal e na angústia da difícil adaptação a um novo contexto sociolinguístico. Assim, o autor apresenta um discurso próprio sobre a identidade portuguesa na sua travessia da Ponte da Cal, ao repescar no legado da romanização as raízes geográficas e culturais, o património genético, arquitetónico e sociolinguístico (idem: 157-162), num reencontro com os nossos antepassados: "Eram, também eles, portugueses? Sim, claro. Com outros nomes que atribuíam a si próprios, mas eram sangue do nosso sangue" (idem: 161).

Não se poderá esquecer que o autor dedica vinte e quatro páginas ao dia 7, persistindo na descontinuidade do ritmo narratológico, conduzido engenhosamente pela mão de um escritor que foge estrategicamente à dispersão, regressando sempre ao trilho previamente delineado, intencionalmente deixado em suspenso, garantindo, porém, a sequencialidade espácio-temporal. Encontrada a rota desejada para o cumprimento do trekking, o sujeito viático critica a organização dos Caminhos de Santigo e o da Rota das Carmelitas, clarificando a diferença entre peregrino e caminhante: "o peregrino procura espiritualidade, o caminhante, encontra-a durante o caminho." (idem: 165)

Seguem-se fragmentos outros que mantêm a continuidade do itinerário cadilhiano com referências interculturais como o caso do rubber time ou tempo elástico, aqui dando a ver velhos hábitos de um globetrotter que se rege pelo "[...] fuso horário das latitudes tropicais" (ibidem), numa nação em que opta por sobressair numa espécie de dupla pertença, aqui entendida na assunção de uma atitude cosmopolita face ao ritmo próprio do caminhante que se desloca no seu país, indiferente aos rituais das refeições e às rotinas do ser português, sendo olhado como se fosse um estrangeiro: "Imagino o que estarão a pensar: que não tenho horas nem modos de português. De facto, não me sinto neste fuso horário." (idem: 166) Para além deste aspeto, não deixam de ser significativas as alusões à comida portuguesa inevitavelmente enraizada na nossa identidade e no nosso património genético e sociocultural em comparação com a dos outros povos, o que acaba por levar o narrador a demarcar-se e a defender uma visão muito particular destes hábitos de cozinha regional, como observa: "É verdade que a comida portuguesa é a melhor do mundo, mas só é verdade para os portugueses que gostam dela" (idem: 166-167).

Impõe-se ainda referir em termos sociais e interculturais que o viajante-textual também se cruza com o Outro ou melhor com a imigração em Alforge, com destaque para a britânica, dando voz a estes estrangeiros que escolheram Portugal para viver e para morrer. Neste caso, trata-se do anúncio do óbito de um inglês que escolheu Alforge como um "[...] destino para expatriados britânicos, provavelmente reformados e com força ainda para mudar radicalmente de vida." (idem: 168) Com efeito, considerações como estas, levam-nos a olhar por dentro um país que mais do que assomar como um refúgio para certas comunidades estrangeiras, sobretudo a brasileira, é encarado também como um território seguro e já reconhecidamente multicultural. Porém, tal acolhimento presente não deixa de ser irónico, se pensarmos numa nação ferida pelas agruras da diáspora portuguesa da década de sessenta, sobretudo, aqueles que se deslocaram para a França e outros para a ex-colónias portuguesas, tanto em África como na Ásia. 
Depois de enquadrado este excurso por um Portugal que tendeu a globalizar-se, é o momento do narrador avançar no itinerário rumo a Coimbra e também para o regresso de Cadilhe ao seu projeto de ficção, engendrando com mestria um enredo medieval das lutas contra os mouros, numa profunda exaltação patriótica de D. Afonso Henriques enquanto rei conquistador para assim justificar o nome do castelo Germanelo (idem: 168-169), apostando habilmente entre a factualidade e a ficção. À semelhança das outras interrupções intencionais do relato viático, esta serve não apenas para lembrar ao leitor a narrativa de viagem do santo, bem como para ressaltar o papel polarizador do autor na escrita fragmentária, prosseguindo o trekker o seu curso entre Alvorge e Rabaçal, cruzando-se com peregrinos estrangeiros, a par da inclusão de reflexões autobiográficas, acontecendo, por fim, a chegada a Rabaçal: "[...] um cruzamento do mundo. Caminhantes de diferentes idiomas conversam animadamente nos cafés e passeiam pela rua principal, trocam notas, dicas, tentam o contacto com os habitantes da cidadezinha." (idem: 173)

Para finalizar o trajeto, Cadilhe atribui ao Dia 8 (idem:175-195) uma simbologia ontológica e espiritual que remete para uma ideia de processo em devir, como se infere das seguintes reflexões do viajante-textual: "O facto de o caminho terminar hoje faz parte do caminho" (idem: 175) ou "Quando arranquei de Lisboa, o meu destino era Coimbra. Depois de todos estes dias a caminhar, compreendo que o meu destino é o próprio caminho" (ibidem), deixando muito claro o seu ofício de viajante e de escritor, numa estimulante inquietação pela viagem, mas também pela escrita deste livro. Na verdade, o dia 8 é constituído por onze fragmentos da viagem até Coimbra e três dedicados ao desfecho da estória do pequeno António. ${ }^{26}$ Deste modo, no âmbito da sobredita simbologia, logo a abrir as duas primeiras páginas do oitavo e derradeiro dia de viagem real por este Portugal acima, o narrador reflete sobre o ato de caminhar na sua aceção metafórica, num contexto instigante à problematização dos laços de pertença a um lugar e assim pensar a identidade portuguesa associada ao património genético e também territorial ou geográfico, como sublinha: "É este o significado mais profundo de raízes, de pertença a um lugar" (idem: 176).

Assim sendo, parece, de facto, importante que mais do que fazer o primeiro "trekking da História de Portugal", Cadilhe questione a identidade nacional a partir não apenas de uma poética dos lugares, mas mormente, através do enredo de processos vivenciais de uma caminhada a que se associa uma condição de pátria: "Através dos nomes dos lugares que atravessei, a minha caminhada conecta-se a um passado mítico de construção e consolidação de uma pátria." (idem: 179) Não por acaso, o autor ecoa no pequeno António esse paralelismo situacional da viagem à distância de séculos, pois "[...] as viagens de um lugar para outro foram a base do crescimento desta nação. Foram corpo que produziram um sangue único, nosso. As estradas são os ossos da História de Portugal." (idem: 180) Após uma intermitência da narração da viagem real, Cadilhe regressa à narrativa ficcional e à aproximação do desfecho da viagem do pequeno António.

Por conseguinte, a viagem pela escrita acontece num olhar interno da condição de um Portugal contraditório e multifacetado, por vezes, poético e patriótico, na sua versão exaltante de um povo que se abre ao mundo através dos Descobrimentos e da sua presença de Portugal no 
Oriente, e das suas figuras de notáveis como o mito D. Sebastião ou de Camões, outras vezes, patético, acutilante e corrosivo herdeiro de um passado glorioso, maculado pelos erros nefastos de um império colonial, que Cadilhe soube tão bem interpretar à luz do século XXI.

Se o fundo de referências ficcionais começa por estar associado ao património coletivo da História de Portugal, concretamente, à hagiografia ou tão-só à figura universal de Santo António, logo se cruza com a esfera individual corporalizada ou espiritualizada (?) no trekking do sujeito textual tendo como itinerário ora um Portugal contemporâneo global ora um país profundo, fruto do rescaldo de um certo obscurantismo legado pelo Estado Novo. Leiam-se as palavras finais do sujeito viático:

Descoberta, purificação, catarse. Metamorfose. Não tenho a depressão do dia seguinte. Não preciso de enfrentar o caminho de regresso nem voltar à vida que deixei no início da peregrinação. Na realidade, eu não sou um peregrino. Sou um escritor que caminha, voilà! Escolho uma mesa. Apoio a mochila, os bastões da caminhada, o chapéu numa cadeira. Gracejo com o dono do bar: «felizmente, as coisas já não são como eram».

Ele não percebe.

Sento-me, tomo o café, pego no bloco de notas e começo a escrever este livro. (idem: 195)

Pelo que ficou dito, resta apenas lembrar que a viagem a esse outro nível de um país narrado, por vezes, quase anacrónico em que o tempo se dilui e/ou cristaliza, sendo palco de peregrinações com rotas bem definidas, constitui uma prova inegável de que o imaginário português não se reduz ao replicar de velhos hábitos, é antes de tudo, uma construção em devir cujos trilhos acabam por instigar reflexões sobre a identidade e/ou condição portuguesa atual, visto pela lente de um escritor-viajante que tendo já a experiência da viagem pelo mundo, dá-se, conta que, afinal, tinha Portugal aqui tão perto!

\section{NOTAS}

\footnotetext{
* Maria Dulce Soares é membro integrado do Instituto de Literatura Comparada Margarida Losa, pertence ao grupo de investigação Inter/Transculturalidades, tendo como principais áreas de indagação a Literatura Comparada, a Literatura de Viagens, os Estudos Interartísticos e o cinema. Docente e investigadora, doutorou-se em Estudos Literários, Culturais e Interartísticos (Estudos Comparatistas), pela Faculdade de Letras da Universidade do Porto, com uma tese intitulada Entre vozes e espelhos: um olhar sobre a Literatura de Viagens contemporânea portuguesa (2018), dando a ver uma panorâmica significativa do estado atual da Literatura de Viagens portuguesa. Realizou o mestrado em Literatura e Cultura Comparadas na mesma faculdade
} 
com a dissertação Gonçalo Cadilhe e a Outra face do Mundo: viagens sobrepostas (2009). Do seu currículo constam algumas publicações no âmbito desta unidade de investigação centradas em estudos críticos nestes domínios e tem participado como oradora e conferencista em colóquios, jornadas, e na organização de atividades no âmbito do projeto estratégico do grupo, numa perspetiva de investigação-ação.

${ }^{1}$ Cf. A obra do autor Nos Passos de Magalhães. Uma Biografia Itinerante (2008), foi já objeto de estudos críticos, designadamente de Maria de Fátima Gil (2016), "Nos Passos de Magalhães de Gonçalo Cadilhe: viagem, evocação histórica e diálogo intercultural", Cadernos de Literatura Comparada, $\mathrm{n}^{0} 34$ - Viagens e Outros Labirintos, Porto, Instituto de Literatura Comparada Margarida Losa, pp.173-189,http://ilccadernos.com/index.php/cadernos/issue/view/27/showToc, consultado em 13/03/2021 e ainda no âmbito da minha tese de doutoramento em Estudos Literários, Culturais e Interartísticos, Porto, Faculdade de Letras da Universidade do Porto, intitulada Entre vozes e espelhos: um olhar sobre a Literatura de Viagens portuguesa contemporânea (2018).

${ }^{2}$ Entre outros, Gonçalo Cadilhe realizou um documentário sobre Fernão Mendes Pinto para a RTP em 2010. https://www.rtp. pt/programa/tv/p27058, consultado em 17/04/2020.

${ }^{3}$ A propósito da relação intermedial com a narrativa de viagem, de resto, sobejamente explorada nas obras do autor, note-se a sua observação no livro Um lugar Dentro de Nós (2012):

Ao contrário do que tinha sido adoptado em todos os meus outros livros, aqui não há qualquer relação entre as fotos e os textos. A única relação que existe entre cada foto ou qualquer outra página do livro encontra-se no pequeno excerto do capítulo "Luz" que abre o caderno de fotografias. É o ponto de atracção e de passagem de todas as imagens [...]. (Cadilhe 2012: 13)

${ }^{4} \mathrm{O}$ autor trabalha com agências de turismo realizando viagens temáticas.

${ }^{5}$ Este termo é da autoria da investigadora Linda Hutcheon para definir o que entende ser uma forma específica de metaficção que implica uma livre interpretação da factualidade histórica, tendo por base fragmentos do património cultural, geográfico e humano: "a theoretical self-awareness of history and fiction as human constructs (historiographic metafiction) [that] is made the grounds for [a] rethinking and reworking of the forms and contents of the past" (Hutcheon 1988: 5).

${ }^{6}$ Dado o seu cariz de permeabilidade, Bill Ashcroft, Gareth Griffiths e Helen Tiffin propõem a seguinte definição do conceito de fronteira:

The idea of a frontier, a boundary or a limiting zone to distinguish one space or people from another, is clearly much older and used more widely than in colonial and postcolonial theory. [...] Colonial frontiers were created as imperial discourse sought to define and invent the entities it shaped from its conquests. The numerous ruler-straight frontiers of imperial maps indicate how colonial cartography existed as much to record actual features and distinctions between various places and peoples. The frontier or boundary that limited the space so defined was a crucial feature in imagining the imperial self, and in creating and defining (othering) those others by which «Self» could achieve definition and value. (Ashcroft et al. 1995: 107-108)

${ }^{7}$ Gonçalo Cadilhe foi agraciado com o Prémio de Jornalismo de Viagens (2011), instituído pela Halcon e pelo Clube de Jornalistas com o relato de uma viagem pelo rio Mekong, no Sudoeste asiático em 2011. http://lifestyle.publico.pt/noticias/304469_goncalo-cadilhe-ganha-premio-de-jornalismo-de-viagens, consultado em 5/02/2021.

${ }^{8} \mathrm{Cf}$. "Nós éramos grandes, dessa grandeza que os outros percebem de fora e por isso integra ou representa a mais vasta consciência da aventura humana, mas éramos grandes longe fora de nós, no Oriente de sonho ou no Ocidente impensado ainda." (Lourenço: 2020: 26).

${ }_{9}$ Cf. Soares, Maria Dulce (2009), Gonçalo Cadilhe e a Outra face do mundo: viagens sobrepostas. Tese de Mestrado em Literatura e Cultura Comparadas, Porto, Faculdade de Letras da Universidade do Porto. 
Cadernos de Literatura Comparada

Gonçalo Cadilhe nos trilhos de Santo António em Portugal

${ }^{10}$ Trata-se da famosa expressão de Marc Augé que caracteriza um espaço transitório, porque "[...] não pode definir-se, nem como identitário, nem como relacional, nem como histórico." (Augé 2005: 67). Note-se, a propósito, o seguinte exemplo: "Caminho por uma estrada semiabandonada, um corredor entrincheirado entre a Linha do Norte à minha esquerda, mais para lá o barulho da A1, e a sugestão do Tejo na distância à direita." (Cadilhe 2020: 49) Ou ainda "Estamos numa estrada nacional. Caminho pela berma, mas nem aqui me sinto seguro. Mesmo os carros que se afastam um pouco para o centro da faixa de rodagem me parecem demasiadamente perto" (idem: 97).

${ }^{11}$ De notar que Gonçalo Cadilhe já tinha realizado a viagem nos passos de Santo António, em 2016, para a escrita do livro homónimo sobre as deslocações do santo. De resto, não é nova a incursão do autor por territórios da metaficção historiográfica. ${ }^{12}$ Trata-se de um conjunto de fotografias sem paginação atribuída e localizada entre as pp. 128 e 129.

${ }^{13}$ Considerando a complexidade do papel do escritor-viajante ao construir a sua narrativa de viagem, Álvaro Manuel Machado e Daniel-Henri Pageaux afirmam que "[...] todo o viajante é um mentiroso, pelo próprio facto de que conta a sua história, de que conta histórias." (Machado/Pageaux 2001: 34). Ora, esta tendência natural para a efabulação é explicada da seguinte forma: "Queremos dizer com isto que o escritor-viajante, ao tentar fazer obra literária, vai efabular. E o importante, do ponto de vista do estudo literário, é observar segundo que lógica se vai construir esta espécie de «mentira», segundo que fantasia criadora se vão desenvolver as confidências do viajante" (ibidem).

${ }^{14}$ Cf. "Na distância atrás de mim, ouço o clicar do obturador. Sacudo a divagação da mente, controlo no ecrã da máquina se a imagem saiu como eu queria, retomo o caminho, desço pela estrada de gravilha para o vale encantado" (Cadilhe 2020: 170). ${ }^{15}$ Ao caracterizarem o relato de viagem ou as experiências da mesma, Álvaro Manuel Machado e Daniel-Henri Pageaux dão particular relevo à "viagem retranscrita" (Machado/Pageaux 2001: 34) que pode formalizar-se no imaginário de escritor-viajante e não limitar-se à expressão narrativa, como observam: "Na narrativa de viagem, o escritor-viajante é ao mesmo tempo produtor da narrativa, objecto, por vezes privilegiado, da narrativa, organizador da narrativa e encenador da sua própria personagem. Ele é assim narrador, actor, experimentador e objecto da experiência. Ou ainda, o memorialista dos seus feitos e dos seus gestos, herói da própria história que inventa e que arranja à sua maneira, testemunha privilegiada em relação ao público sedentário e, enfim, contador para gáudio deste" (ibidem).

${ }^{16}$ Cf. "Não era ainda nem santo nem António. Chamava-se Fernando. Teria de apelido Martins" (Cadilhe 2020: 30).

${ }^{17}$ Impõe-se notar que estamos perante micronarrativas que obedecem a uma estrutura fragmentária descontínua e que acabam por cruzar com a narrativa viática protagonizada pelo narrador-viajante, a assegurar a sua progressão: incipit, desenvolvimento e conclusão. De notar que Cadilhe opta pela sua inclusão de um modo diluído e garantindo sempre uma articulação com a deslocação real. O telling da viagem de Fernando Martins é assim feito, ao longo das seguintes páginas da obra em apreço: 31-33; 40-41; 54-55: 71-72: 79-80; 84-85; 100-101; 105-106: 122-123: 132-133; 147-149; 163; 168-169; 180-181; 187$188 ; 191-192$.

${ }^{18}$ No sentido no sentido que lhe é atribuído por Fernanda Irene Fonseca:

O que é designado como texto fragmentário ou descontínuo é uma sequência de textos curtos (ou por vezes longos), separados graficamente por um espaço, e cuja sequencialização não obedece a critérios de ordenação de tipo textual/discursivo, uma vez que não se estabelecem, entre os textos alinhados em sequência, nem ligações formais marcadas pelo uso de conectores ou operadores diafóricos, nem relações de continuidade/progressão temática ou outra.

A fragmentação afecta, portanto, a sequencialização dos textos e não a estrutura de cada um deles, pelo que me parece mais apropriado falar de macro-textualidade fragmentária ou descontínua para designar esse tipo de organização macro-textual que tem como característica específica a falta de unidade, quer ao nível da sintaxe macro- textual quer da continuidade/progressão temática global. (Fonseca 2004: 346-347) 
${ }^{19}$ Cf. "Imagina-te, leitor, a teres de ir a pé até Coimbra para poderes ler o meu livro..." (Cadilhe 2020: 31).

${ }^{20}$ Cf. "Nota Introdutória":

A minha caminhada demorou oito dias e foi uma peregrinação no sentido mais lato do termo: não religiosa, mas certamente espiritual. Foi também um reencontro com as paisagens, a História e os ambientes culturais da minha pátria. E foi um longo, preguiçoso devaneio por memórias e momentos formativos da minha vida. Foi portanto uma experiência pessoal e bastante introspetiva, mas tão luminosa e inspiradora que quis que fosse partilhada contigo. (idem: 15)

${ }^{21}$ Para além da habitual convocação de escritores e respetivas obras, Gonçalo Cadilhe alude aos seus livros e recorre ao processo da autocitação. Cf. as pp. 21, 45, 124-125, entre outras.

${ }^{22}$ Cf. Canto V d'Os Lusíadas estâncias 92-100, quando o poeta censura os seus contemporâneos que desprezam a arte e a poesia necessárias para o conhecimento e o louvor dos feitos de um povo de heróis.

${ }^{23}$ Cf. "Perturbado [o rapaz], perguntou-se se deveria considerar aquelas emoções como pecados graves de paganismo e abjuração da santa fé, ou apenas um modo mais puro e intenso de se envolver com a beleza e o mistério da obra divina? Apetecia-lhe abraçar os lobos, ensinar o Evangelho aos pássaros, pregar sermões aos peixes, saudar o sol como um irmão e amar a Morte como uma irmã. "(Cadilhe 2020: 84).

${ }^{24} \mathrm{Cf}$. "Caminho pelas ruas em esquadria do bairro antigo e sinto-me recuperado, refeito, como novo. Fez-me bem interromper a caminhada durante alguns dias, ocupar a minha cabeça com outros assuntos e voltar à cidade - habitat congénito de quase toda a humanidade no mundo em que efectivamente vivemos. Quem diria que o ser humano chegaria a um ponto da sua linha evolutiva em que a permanência nos bosques seria anti natura e o regresso à cidade um regresso às origens?" (Cadilhe 2020: 129).

${ }^{25}$ Trata-se de um ritual napolitano que consiste em oferecer um café a um cliente do bar em sinal de alegria e/ou cortesia. Tal como refere o sujeito viático, convocando novamente a sua biblioteca mental: "O hábito napolitano chama-se o café pendente e está muito bem descrito no livro do filósofo napolitano Luciano di Crescenzo com o mesmo título, mais precisamente Il Caffe Sospeso" (Cadilhe 2020: 130).

${ }^{26}$ Cf. pp. $180-181 ; 187-188 ; 191-192$.

\section{Bibliografia}

Ashcroft, Bill/ Gareth Griffiths/ Helen Tiffin, (1995), Post-colonial Studies, London, Routledge. Augé, Marc (2005), Não-Lugares. Introdução a uma Antropologia da Sobremodernidade, trad. de Miguel Serras Pereira, Lisboa, 90 Graus Editora.

Barrento, João (1996), "O Poeta é um devedor: da tradução literária e da história da literatura" in Literatura Comparada: os novos paradigmas, Margarida L. Losa, Isménia de Sousa e Gonçalo Vilas-Boas (orgs.), Porto, Associação Portuguesa de Literatura Comparada, pp. 189-196. 
-- (2010), O Género Intranquilo, anatomia do ensaio e do fragmento, Lisboa, Assírio \& Alvim.

Cadilhe, Gonçalo (2008), Nos Passos de Magalhães. Uma Biografia Itinerante, Cruz Quebrada, Oficina do Livro.

-- (2012), Um Lugar Dentro de Nós, Lisboa, Lisboa, Clube do Autor.

-- (2016), Nos Passos de Santo António. Uma viagem medieval, Lisboa, Lisboa, Clube do Autor.

-- (2020), Por este Reino Acima. No primeiro trekking da História de Portugal, Lisboa, Clube do Autor.

Camões, Luís de (1973), Os Lusíadas, Porto, Porto Editora.

Castilllo, José Romera (2006), "Fragmentariedad diarística: sobre Miguel Torga", Forma breve.

Revista de Literatura, 4, o fragmento, Aveiro, Edição Universidade de Aveiro, pp. 107-124.

Ette, Ottmar (2003), Literature on the Move, translated by Kattharina Vester, New York, Rodopi. Fonseca, Fernanda Irene (2004), "Fragmentação e unidade: contributos para a análise de formas textuais intencionalmente fragmentárias" in Da língua e do Discurso, Fátima Oliveira e Isabel Margarida Duarte (orgs.), Porto, Campo das Letras, pp. 345-362.

-- (2008), "Tempo de Mudança: análise de um diário inédito (1944-1949) de Vergílio Ferreira" in O Fascínio da Linguagem, Actas do Colóquio de homenagem a Fernanda Irene Fonseca, Fátima Oliveira e Isabel Margarida Duarte (org.), Porto, Centro de Linguística da Universidade do Porto/Faculdade de Letras da Universidade do Porto, pp. 3-28.

Garrett, Almeida (2016), Viagens na Minha Terra, Porto, Porto Editora.

Gil, Maria de Fátima (2016), "Nos Passos de Magalhães de Gonçalo Cadilhe: viagem, evocação histórica e diálogo intercultural", Cadernos de Literatura Comparada, nº34- Viagens e Outros Labirintos, Porto, Instituto de Literatura Comparada Margarida Losa, pp.173-189, <http://ilccadernos.com/index.php/cadernos/issue/view/27/showToc, > (último acesso em 13/03/2021)

Hyland, Paul (1997), Backwards out of the big world: a voyage into Portugal, London, Flamingo New Edition.

Hutcheon, Linda (1988), A Poetics of Postmodernism. History, Theory, Fiction, NY and London, Routledge.

Lejeune, Phillipe (2005), Signes de vie: le pacte autobiographique 2, Paris, Éditions du Seuil. Lourenço, Eduardo (2020), O Labirinto da Saudade, Lisboa, Gradiva Publicações, S. A.

Machado, Álvaro Manuel e Pageaux, Daniel-Henri (2001), Da Literatura Comparada à Teoria da Literatura, Lisboa, Editorial Presença.

Outeirinho, Maria de Fátima (2008), "Fragmentos e Narrativas de Viagem" in O Fascínio da Linguagem, Actas do Colóquio de Homenagem a Fernanda Irene Fonseca, Fátima Oliveira e Isabel Margarida Duarte (orgs.), Porto, Centro de Linguística da Universidade do Porto/ Faculdade de Letras da Universidade do Porto, pp. 309-314.

Soares, Maria Dulce (2009), Gonçalo Cadilhe e a Outra face do mundo: viagens sobrepostas. Tese de Mestrado em Literatura e Cultura Comparadas, Porto, Faculdade de Letras da Universidade do Porto. 
- - (2018), Entre vozes e espelhos: um olhar sobre a Literatura de Viagens portuguesa contemporânea. Tese de Doutoramento em Estudos Literários, Culturais e Interartísticos, Porto, Faculdade de Letras da Universidade do Porto.

Sontag, Susan (2012), Ensaios sobre Fotografia, trad. de José Afonso Furtado, Lisboa, Quetzal Editores.

Zavala, Lauro (2006), "Fragmentos, fractales y fronteras: género y lectura en las series de narrativa breve", Forma breve. Revista de Literatura, 4, O fragmento, Aveiro, Edição Universidade de Aveiro, pp. 35-52.

<https://www.rtp.pt/programa/tv/p27058 > (último acesso 17/04/2020).

<http://lifestyle.publico.pt/noticias/304469_goncalo-cadilhe-ganha-premio-dejornalismo-de-viagens>, (último acesso 5/02/2021). 